\title{
O Ministério Público nas Unidades de Conservação do Corredor Central da Mata Atlântica: uma avaliação a partir do discurso dos Promotores de Justiça
}

\section{The Public Attorney in the Conservation Units of the Central Corridor of the Atlantic Rain Forest: an Evaluation of the Justice Prosecutors Testimonies}

\author{
Soraya Carvalhedo HONORATO* \\ Isabel Maria Sampaio Oliveira LIMA** \\ Déborah Maria de FARIA** \\ Sérgio dos Anjos MENDES M*** $^{* *}$
}

\begin{abstract}
RESUMO
Esse artigo pretende analisar a atuação do Ministério Público na defesa do meio ambiente em Unidades de Conservação localizadas no Corredor Central da Mata Atlântica na Bahia. A abordagem metodológica adotada foi de natureza qualitativa, realizando-se um estudo de caso a partir das técnicas de análise documental e dos depoimentos dados nas entrevistas. Os documentos analisados foram os Termos de Ajustamento de Conduta, entre 2004-2006, levantados nas comarcas, e os relatórios das oficinas de capacitação desses promotores. Para realização das entrevistas utilizou-se a história oral e, para o tratamento deste acervo, o discurso do sujeito coletivo. Colhidos e analisados depoimentos dos Promotores de Justiça lotados em comarcas com unidades de conservação constatou-se que os operadores do Direito ainda não dominam claramente os objetivos e os propósitos das diferentes estratégias de conservação, concluindo-se que esta circunstância reverbera na práxis ministerial da proteção ambiental. Há deficiências quanto à infraestrutura, pessoal e equipamentos que restringem igualmente a atuação institucional. Os termos pactuados nas comarcas estudadas no período não surtiram efeitos concretos para a conservação.

Palavras-chave: unidade de conservação; termo de ajustamento de conduta; Ministério Público; proteção ambiental.
\end{abstract}

\footnotetext{
"Engenheira Florestal, Mestre em Desenvolvimento Regional e Meio Ambiente. PRODEMA/Universidade Estadual de Santa Cruz - UESC. Email: sol.honorato@ gmail.com

"* Doutora em Saúde Pública. Juíza de Direito do Estado da Bahia e Professora da Universidade Católica de Salvador - UCSAL. Email: isabelmsol@gmail.com

*** Bióloga, Doutora em Ecologia. Professora Titular da Universidade Estadual de Santa Cruz (UESC). Email: deborahuesc@gmail.com

**** Promotor de Justiça de Meio Ambiente em Salvador. Email: antoniosergiomendes@gmail.com
} 


\begin{abstract}
This article aims to analyze the performance of the of Public Attorney in defense of the environment in protected areas located in the Central Corridor of the Atlantic Forest in Bahia. The methodology adopted is qualitative, performing a case study from the techniques of analysis of documents and testimonials given in interviews by the Justice Prosecutors involved in this study. The documents examined were the extrajudicial procedures (Conduct Adjustment Agreement), raised in counties between 2004-2006, and the reports produced by these Justice Prosecutors in the training workshops. In order to produce the interviews we had utilized the Oral History as a technique. For treatment of the collection of interviews we used the collective subject discourse. The retrieval and the analysis of the testimonies by the Justice Prosecutors, who are stationed in counties with protected areas, showed that these professionals do not clearly dominate the objectives and purposes of different conservation strategies. We conclude that this fact has consequences on the public attorney's actions in the environmental protection. There are deficiencies in infrastructure, personnel and equipment that restrict the institutional activities. The terms agreed upon in the regions studied in the period had no concrete effects to conservation.
\end{abstract}

Key-words: conservation units; conduct adjustment agreement; Public Attorney; environmental protection.

\section{Introdução}

A Mata Atlântica é a segunda maior floresta pluvial tropical do continente americano, presente no leste do Paraguai, nordeste da Argentina e no Brasil. Neste país é o terceiro maior bioma em extensão geográfica, ocupando toda a faixa continental atlântica leste e estendendo-se para o interior do Sudeste e Sul. Variados ecossistemas encontram-se associados ao bioma, tais quais os manguezais, as restingas, as formações campestres de altitude e os brejos interioranos. Com vegetação florestal predominante e relevo diversificado, a Mata Atlântica ocupa a totalidade territorial do Espírito Santo, do Rio de Janeiro e da Santa Catarina, 98\% do Paraná, além de áreas de outras 11 unidades da Federação. Originalmente esse bioma cobriu mais de 1,5 milhões de $\mathrm{km}^{2}$, sendo $92 \%$ desta área no Brasil (GALINDO-LEAL; CÂMARA, 2005; IBGE, 2010; TABARELLI et al., 2005).

A Mata Atlântica é relevante por abrigar espécies com alto nível de endemismo em suas três sub-regiões, dentre as quais o litoral Sul da Bahia (MORI et al., 1983), centro das atenções nas políticas públicas de conservação, a exemplo do Projeto Corredores Ecológicos. Ocorre que a integridade desta sub-região está ameaçada (SILVA; CASTELETI, 2005) por iguais fatores registrados em pesquisas conduzidas em outras áreas protegidas e biomas. Theulen (2004) constatou gestão deficiente dos recursos naturais também na Mata Atlântica, elegendo como fator limitante a insuficiência de Unidades de Conservação (UC) repre- sentativas e adequadamente dimensionadas para atender as necessidades de hábitat de algumas espécies. Floriani et al. (2007), em contexto similar ao da sub-região em voga, apontam como ameaça a ausência de planejamento e gestão territorial no desenvolvimento dos municípios. Ainda, a expansão desenfreada de infraestrutura urbana em áreas de preservação permanente e a exploração ilegal de recursos foram destacadas por Câmara (2004) e Machado (2006) como fatores de impacto ambiental negativos à manutenção das espécies.

Este cenário contextualiza a importância do Núcleo da Mata Atlântica (NuMA), um grupo especial de 110 Promotorias de Justiça, criado pelo Ministério Público (MP) do Estado da Bahia para atuar ao longo de todo o litoral Sul do Estado, sistematizado em seis Coordenações Regionais: Costa do Cacau, Costa do Descobrimento, Costa das Baleias, Costa do Dendê e Baía de Todos os Santos.

O MP representa, em face da sua missão constitucional e na perspectiva da proteção ambiental, uma instituição estratégica, sobretudo quando exerce o papel de fiscal no controle da administração pública para efetivo cumprimento das leis ambientais, consoante a Norma Jurídica Complementar n. ${ }^{\circ}$ 11/1996, que institui a Lei Orgânica do Ministério Público do Estado da Bahia (BAHIA, 1996). O NuMA, no entanto, enseja transcender a sua função fiscalizadora, agindo como protagonista em prol da seguridade ambiental, seja na capacitação dos promotores de justiça, seja no fortalecimento da relação institucional entre o órgão e os representantes da sociedade civil e do Poder Executivo. 
Assim sendo, o NuMA, no dizer de Honorato et al. (2010, p. 4), se apercebe como:

[...] um elo forte entre o Poder Executivo e o Poder Judiciário: (i) porque tem o respaldo legal para impor ao infrator a mitigação, cessação ou impedimento dos impactos ambientais sugeridos por fiscais ambientais do Poder Executivo; (ii) porque pode tornar factual a conservação in loco mediante os acordos extrajudiciais, também baseados em laudos periciais e relatórios de fiscalização emitidos pelo Poder Executivo; e (iii) sobretudo, porque pode provocar o Poder Judiciário a educar e punir esses infratores, oferecendo como materialidade do fato (a infração ou crime ambiental) as provas do crime que são os laudos, relatórios técnicos, notificações e autos de infração (multas, embargos e demolições) administrativos emitidos por fiscais ambientais habilitados, também desse mesmo poder executivo.

\section{Estratégias de conservação em diferentes escalas: Corredores Ecológicos e Unidades de Conservação}

A maioria das espécies vive em paisagens fragmentadas, ou seja, seu hábitat original foi reduzido de tamanho e o que restou ainda encontra-se representado por pequenas manchas separadas entre si por outros tipos de uso da terra. Os efeitos deletérios da sinergia entre a redução de hábitat e sua fragmentação sob a biota são conhecidos e de forma geral implicam que as populações pequenas e isoladas aumentam a sua probabilidade de extinção pela diminuição do hábitat disponível, ao mesmo tempo em que a recolonização dos fragmentos é reduzida devido ao isolamento populacional destas manchas (HANSKI, 1998).

Daí depreende-se a importância de estratégias tais quais os Corredores Ecológicos, que incluem na sua concepção a necessidade de manejar não apenas os espaços protegidos (fragmentos de hábitat), mas também os hábitats de interstício (matriz), que podem ser adequadamente geridos para favorecer o deslocamento de indivíduos na paisagem como um todo. Portanto, a ideia de Corredores Ecológicos parte da noção de que é importante manter o fluxo gênico entre as subpopulações ${ }^{1}$ e, desta forma, restabelecer a conectividade entre os hábitats remanescentes. Nestes termos, facilita o movimento das metapopulações entre as manchas de hábitat, aumentando a diversidade de espécies e genes em áreas que, de outra forma, seriam isoladas (RAMBALDI; OLIVEIRA, 2003). Os corredores também são importantes porque a integração e as interconexões de hábitats estabelecidos fomentam a cooperação entre as representações de interesses públicos e privados. Considerando que o manejo de ecossistemas fora de UC será cada vez mais crítico para a sobrevivência de espécies ameaçadas, faz-se necessário impulsionar a conservação de terras em propriedades privadas e estimular o manejo sustentável.

O termo "corredores ecológicos" foi amplamente discutido e sob diversas concepções no Brasil (PRADO et $a l ., 2003$ ) e no mundo (BEIER; NOSS, 1998). O conceito que vigorou na política de conservação do Brasil, contudo, foi aquele proposto por Ayres et al. (1997), que é adotado pelo Ministério do Meio Ambiente - MMA - no Plano-Piloto para Florestas Tropicais (PP-G7) e que trata da gestão de paisagens em grandes escalas. Não obstante, o PP-G7 se alicerça na ausência de aparato legal para implantação de corredores em larga escala porque o seu conceito de corredores distinguiu-se daquele previsto no bojo do Sistema Nacional de Unidades de Conservação que os têm tão somente para conectar as Unidades de Conservação (GANEM, 2005).

Os Corredores Ecológicos consubstanciam-se em sete grandes áreas que perfazem cerca de $25 \%$ das florestas tropicais úmidas do Brasil. Cinco deles estão localizados na Amazônia: Corredor Central da Amazônia, Corredor Norte da Amazônia, Corredor Oeste da Amazônia e dois ecótonos sul-amazônicos. Dois Corredores estão na Mata Atlântica: o Corredor Central e o Corredor Sul ou da Serra do Mar. Os Corredores Centrais da Amazônia (CCAM) e da Mata Atlântica (CCMA) foram eleitos prioritários com o propósito de testar este modelo de gestão em diferentes condições nestes biomas e a partir das lições aprendidas, preparar e apoiar a implantação dos demais corredores (MMA, 2002).

Abrangendo todo sul da Bahia e o Estado do Espírito Santo, o CCMA perfaz uma área de 8,5 milhões de hectares,

\footnotetext{
${ }^{1}$ Áreas de hábitats inadequados frequentemente separam manchas de hábitats adequados; os indivíduos podem se mover através dessas áreas eventualmente, mas não podem persistir nelas. Um conjunto de subpopulações conectadas por movimentos ocasionais de indivíduos entre elas é denominado de metapopulação. Este conceito tornou-se recentemente uma das ferramentas mais importantes da ecologia para a compreensão da dinâmica das espécies que vivem em ambientes fragmentados (ROCHA et al., 2006).
} 
entremeado de florestas ombrófilas, restingas e manguezais nos estuários. Destaca-se pela presença de diversos taxa tipicamente amazônicos associados à costa atlântica e também por possuir mais de $50 \%$ das espécies de aves endêmicas do bioma (CORDEIRO, 2003). Considerando-se apenas as aves, há confirmação da descoberta recente de cinco novas espécies e um novo gênero Acrobatornis no sul da Bahia (AGUIAR et al., 2005).

O Projeto Corredores elegeu, no litoral sul na Bahia, cinco áreas prioritárias e estratégicas para a conservação do bioma Mata Atlântica. Denominou-as de áreas focais: Complexo Camamú-Cabruca-Conduru, Complexo Uma-Lontras-Baixões, Complexo do Descobrimento, Complexo de Abrolhos e Complexo Boa Nova-Conquista (BRASIL, 2005). A escolha dessas áreas teve como subsídio o subprojeto Avaliação e Ações Prioritárias para a Conservação da Biodiversidade nos biomas Floresta Atlântica e Campos Sulinos, no âmbito do Projeto de Conservação e Utilização Sustentável da Diversidade Biológica Brasileira - PROBIO/ MMA (BRASIL, 2000).

Ao contrário do histórico recente dos corredores ecológicos na Brasil, as UC têm seus primeiros registros em 1937, por meio da criação do Parque Nacional do Itatiaia, e em 1939, com os Parques Nacionais Serra dos Órgãos, das Sete Quedas e do Iguaçu. Desde então, as UC, gradativamente, ganham respaldo legal quando as suas diferentes categorias passam a ser registradas em importantes Normas Infraconstitucionais. Foi o que ocorreu no Código Florestal de 1965 (Lei 4.771), com as categorias parque nacional, reserva biológica e floresta nacional.

Posto assim, tais áreas protegidas têm relevância na Política Nacional do Meio Ambiente (Lei 6.938/1981) e estão legalmente reconhecidas e chanceladas na Lei 9.985/2000, que institui o Sistema Nacional de Unidades de Conservação (SNUC). Esta, em seu art. 2. ${ }^{\circ}$, inciso I, assim conceitua as UC:

[...] espaço territorial e seus recursos ambientais, incluindo as águas jurisdicionais, com características naturais relevantes, legalmente instituído pelo Poder Público, com objetivos de conservação e limites definidos, sob regime especial de administração, ao qual se aplicam garantias adequadas de proteção.

O SNUC ainda tratou de estabelecer as categorias de uso, definir os objetivos destas áreas e classificá-las em dois grupos que se diferem quanto ao uso dos recursos naturais, a saber: unidades de proteção integral e de uso sustentável. As unidades de proteção integral devem manter os ecossistemas livres de alterações causadas por interferências antrópicas, admitido tão somente o uso indireto dos seus atributos naturais. Já as unidades de uso sustentável permitem a exploração do ambiente de forma socialmente justa e viável economicamente, garantindo a perenidade dos recursos renováveis, dos processos ecológicos, da manutenção da biodiversidade e dos demais atributos ecológicos.

A mesma lógica de classificação foi replicada pelo legislador no escopo da Lei 10.431/2006, regulamentada pelo Decreto 11.235/2008, que prevê o Sistema Estadual de Unidades de Conservação da Bahia. As UC de proteção integral são assim denominadas: (i) Estação Ecológica; (ii) Reserva Biológica; (iii) Parque Estadual; (iv) Monumento Natural; e (v) Refúgio de Vida Silvestre.

São as UC de uso sustentável: (i) Área de Proteção Ambiental; (ii) Área de Relevante Interesse Ecológico; (iii) Floresta Estadual; (iv) Reserva Extrativista; (v) Reserva de Fauna; (vi) Reserva de Desenvolvimento Sustentável; e (vii) Reserva Particular do Patrimônio Natural. A Lei Estadual acrescenta a esse grupo: (viii) Parques Urbanos; (ix) Horto Florestal e Jardins Botânico, Zoológico e Zoobotânico; e (x) Reserva Particular de Proteção da Biodiversidade.

$\mathrm{O}$ extremo sul da Bahia abriga os últimos grandes remanescentes florestais do Nordeste, parte deles protegidos por quatro unidades de conservação de gestão federal. São os parques nacionais (PARNA) do Descobrimento, Monte Pascoal, Pau Brasil e Abrolhos, que resguardam quase 500 $\mathrm{km}^{2}$ de florestas. As pequenas bacias hidrográficas contidas nessas áreas protegidas são extremamente importantes, tanto para a biodiversidade da Mata Atlântica, quanto para o maior conjunto de recifes de coral da fauna marinha do Atlântico Sul: o parcel de Abrolhos (BRASIL, 2005).

Embora o último levantamento oficial tenha registrado apenas 83 UC dentro dos limites do CCMA, Mesquita et al. (2007) identificaram, recentemente, 112 unidades de conservação, perfazendo uma área de 1.214.180,72 hectares. Esta pesquisa aponta que as UC na Bahia somam uma área de 1.094.501,34 hectares, sendo 11 unidades de proteção integral, 22 unidades de uso sustentável e 28 Reservas Particulares de Patrimônio Natural (RPPN). Há consenso em ambas as fontes de que, no âmbito do CCMA, a Bahia possui cerca de $90 \%$ da superfície destas unidades de conservação, estando os demais $10 \%$ dentro do território do Estado do Espírito Santo. 


\section{A identidade do Ministério Público e suas atribuições legais}

O Ministério Público tem uma dinâmica distinta do restante do funcionalismo público, conforme prevê a matriz constitucional, acumulando as mesmas prerrogativas dos membros do Judiciário que são a vitaliciedade, a inamovibilidade e a irredutibilidade de vencimentos (salário) (BRASIL, 2006). Destaca-se o fato de que o MP não está subordinado ao Poder Judiciário, agindo independente deste e dos outros dois Poderes da República. Seus integrantes são graduados em Direito, selecionados por concurso público, sendo proibida a atuação como advogados de interesses particulares (TEIXEIRA, 2004; FONTES, 2006).

Conforme o caput do art. 225 da Constituição Federal, o meio ambiente é bem de uso comum do povo, portanto pertencente à coletividade, cabendo também ao Poder Público o exercício da sua defesa. Ainda prescinde, em seu art. 170, que a ordem econômica com fins de assegurar a todos uma existência digna deve observar o princípio da defesa do meio ambiente. Diante do quadro que se descortina, reflete-se acerca da missão do MP, atribuída por meio do art. 127 da mesma Carta Magna, qual seja, a defesa da ordem jurídica, do regime democrático e dos interesses sociais e individuais indisponíveis. Posto assim, a atuação ministerial desdobra-se na fiscalização dos poderes públicos para que apliquem os preceitos legais, pretendendo zelar pelo respeito aos direitos constitucionais e garantias dos serviços de relevância pública. Na Bahia, a função de defesa dos interesses coletivos atribuída ao Ministério Público Estadual está mais precisa no artigo 72, inciso I da Lei Complementar n. ${ }^{\circ} 11$ de 1996: promover a defesa do regime democrático e dos interesses sociais e individuais indisponíveis. Outrossim, no mesmo artigo, no inciso IV, o legislador desdobra essa competência dada ao órgão: "promover o inquérito civil e a ação civil pública para a proteção, a prevenção e a reparação dos danos causados ao meio ambiente, ao consumidor, aos bens e direitos de valor artístico, estético, histórico, turístico e paisagístico".

Ante o atual arcabouço jurídico, derivação dos avanços constitucionais do MP, confirma-se que o direito ao equilíbrio ecológico e à sanidade do ambiente não se apresenta mais estanque, vez que destaca-se dentre os direitos fundamentais proclamados na Constituição Federal de 1988. A defesa ambiental nasce do Estado Democrático de Direito e promovê-la, portanto, é responsabilidade civil do MP. Posto que há ao menos um representante do MP na esfera de cada UC do CCMAB e que este goza de todas aquelas prerrogativas já citadas, é factível afirmar o seu grande potencial em tornar-se parceiro (dentro das suas atribuições legais) das agências ambientais do poder executivo e da sociedade civil, responsabilizando os causadores de danos ambientais e adotando medidas judiciais e extrajudiciais para recuperar áreas degradadas e evitar danos ambientais iminentes.

O Termo de Ajustamento de Conduta (TAC), podendo ser municiado de provas colhidas a partir do inquérito civil, é um título executivo extrajudicial para ajustar a conduta do poluidor efetivo ou potencial, tornando-o um compromissário obediente às exigências legais, a fim de evitar que incidam sobre ele as penalidades civis. Destarte, a construção do acordo firmado entre o MP e o infrator ocorre sem a intervenção do poder judiciário; contudo, não sendo cumprido o TAC no prazo estabelecido pelo promotor de justiça, o MP poderá ajuizar uma Ação Civil Pública (judicial).

O TAC tem natureza jurídica de transação, sendo o MP o ente responsável pelo ajustamento da conduta do compromissário às normas legais. É o que prevê a Lei 7.347/1985 (em seu inciso I e $\S 6 .^{\circ}$ do art. 5..$^{\circ}$ ), também nominada de Ação Civil Pública (LACP), que origina e ampara o TAC (MACHADO, 2006). De fato, no contexto ambiental, o título extrajudicial pretende induzir que o compromissário assuma obrigações de recuperar o ecossistema alterado, sendo, tão somente, objeto de negociação a definição do tempo, do modo e o lugar da reparação do dano.

Denota-se aqui a importância do inquérito civil supracitado porque é exclusivo do MP e é constituído de inspeções e diligências investigatórias. Este procedimento administrativo permite, portanto, qualificar o infrator (pessoa física ou jurídica), investigar a ocorrência de potenciais atos lesivos ao meio ambiente, colher depoimentos ou esclarecimentos, requisitar informações, exames periciais (relatórios de fiscalização do IBAMA e dos órgãos fiscalizadores estaduais e municipais) e demais documentos nas três esferas do poder executivo.

\section{O perfil dos promotores de justiça nos Corredores Ecológicos da Bahia}

A área de estudo abrange a porção sudeste da Bahia, estando entre as coordenadas $13^{\circ} 05^{\prime}$ e $18^{\circ} 05^{\prime}$ de latitude 
Sul e $38^{\circ} 50^{\prime}$ e $41^{\circ} 33^{\prime}$ de longitude Oeste (LANDAU; RESENDE, 2003). Encontram-se localizadas nesta região as 25 comarcas que o estudo focou: Alcobaça, Belmonte, Buerarema, Camamú, Camacan, Caravelas, Coaraci, Gandu, Itacaré, Itajuípe, Itapebi, Itabuna, Ilhéus, Jequiriçá, Nilo Peçanha, Pau-Brasil, Prado, Porto Seguro, Santa Cruz de Cabrália, Santa Luzia, Taperoá, Ubaíra, Una, Wenceslau Guimarães e Valença.

Para analisar a atuação do MP na defesa ambiental fez-se uma verificação da visão e do nível de conhecimento técnico do Ministério Público Estadual quanto à matéria ambiental específica. Para tanto, foram colhidos e analisados os depoimentos de 23 Promotores de Justiça lotados nas comarcas desde logo citadas. A análise descritiva também contemplou os TAC dentre os procedimentos e processos levantados nessas comarcas e os relatórios das oficinas ambientais de capacitação dos Promotores de Justiça realizadas até o ano de 2008.

Importa ressaltar que o Ministério Público Federal não foi objeto de análise da pesquisa em tela, vez que demandaria maior orçamento, fosse para a aplicação do Termo de Consentimento Livre e Esclarecido ${ }^{2}$ para os Procuradores, fosse para a análise dos processos nas Procuradorias Federais. Outro fator limitante seria o tempo empregado na obtenção de autorização formal do Procurador-Geral da República, em Brasília.

As comarcas analisadas cumprem os dois critérios de eleição para desenvolvimento da pesquisa: situar-se no Corredor Central da Mata Atlântica da Bahia e possuir pelo menos uma UC nos limites da sua circunscrição jurisdicional (MESQUITA et al., 2004; 2007). Embora a pesquisa envolva 25 comarcas, apenas 23 Promotores de Justiça foram entrevistados, vez que dois deles também atuavam como Promotores substitutos em outras comarcas. Observa-se, ainda, que das 25 comarcas visitadas em três delas os Promotores de Justiça informaram que não havia nenhum procedimento de cunho ambiental no período de 2004 a 2006. Por conseguinte, foram analisados os procedimentos de 22 comarcas.

A análise dos procedimentos dessas comarcas visou verificar: (i) o andamento dos TACs (período cronológico); a localização dos ilícitos investigados; a constatação de existência do dano ambiental; a produção de provas; a descrição do compromissário e do cumprimento e descumprimento das obrigações concernentes ao dano ou ameaça de dano ambiental; a reparação, reversão ou mitigação do dano ambiental ${ }^{3}$; e (ii) a citação de alguma unidade de conservação em tais procedimentos.

A história oral foi o método utilizado para obter informações a partir de fontes primárias, neste caso, os depoimentos dos Promotores de Justiça. O procedimento permite a compreensão de um pretérito ainda não registrado em documentos e privilegia a aproximação do pesquisador com seu objeto de estudo a partir da realização de entrevistas com pessoas que participaram ou testemunharam acontecimentos, conjunturas ou determinadas visões de mundo (ALBERTI, 2004). As entrevistas foram de dois tipos: a entrevista temática e semiestruturada aplicada para os Promotores lotados nas comarcas e a entrevista de história de vida aplicada para o coordenador do NuMA. A escolha desta última técnica se deu em face da natureza singular identificada mediante os próprios Promotores quando se referem à coordenação do NuMA.

O roteiro básico das entrevistas semiestruturadas aplicadas para os Promotores de Justiça constituiu-se das seguintes perguntas: (i) Vossa Excelência sabe dizer se existem áreas protegidas que estão inseridas no distrito desta comarca? Quais? Quantas? (Pergunta 01); (ii) O que Vossa Excelência entende por Unidade de Conservação? (Pergunta 02); (iii) O que Vossa Excelência entende por Mata Atlântica? (Pergunta 03); (iv) O que Vossa Excelência entende por corredor ecológico? (Pergunta 04); (v) Qual a avaliação que Vossa Excelência faz da sua estrutura de trabalho, em geral? (Pergunta 05); (vi) Quais são as três áreas do Direito de sua preferência de atuação? (Pergunta 06); (vii) O que Vossa Excelência acha da utilização da via extrajudicial para sanar omissões do Poder Público na área ambiental? (Pergunta 07).

O discurso do sujeito coletivo (DSC) foi a metodologia escolhida para tratar os dados fornecidos pelos depoentes. Tal técnica propõe reconstruir, com fragmentos de discursos individuais, o discurso-síntese, necessário para expressar a representação social de um fenômeno, aqui configurado como a atuação do MP.

\footnotetext{
${ }^{2}$ Pré-requisito para a aplicação das entrevistas semiestruturadas, conforme determinação do Comitê de Ética em Pesquisa da Universidade Estadual de Santa Cruz - UESC. Tais procedimentos éticos foram observados na atual pesquisa para acessar o Ministério Público Estadual.

${ }^{3}$ Dano ambiental entendido como afetação ao bem jurídico meio ambiente, perturbadora de qualquer um dos seus elementos componentes. O dano implica na extrapolação de padrões de suportabilidade do sistema ecológico (COSTA NETO, 2003).
} 
Segundo Lefreve e Lefreve (2005) o DSC é redigido na primeira pessoa do singular e compõe-se de: (i) expressões-chave que são as transcrições literais do discurso; (ii) ideia central que é um nome ou expressão linguística que revela de maneira mais fidedigna possível o sentido de cada um dos discursos analisados; e (iii) ancoragem, que é uma manifestação explícita de ideologia ou teoria ou crença usada para enquadrar uma situação específica (LEFEVRE; LEFEVRE, 2005).

Na dimensão descritiva, analisando os discursos do conjunto de Promotores de Justiça, seria possível verificar o comportamento destes frente às questões ambientais, bem como suas condições de trabalho, a partir das perguntas norteadoras para tal avaliação: (i) avaliação da pergunta 01 - o Ministério Público está atento quanto às estratégias de conservação dos entes federados (federal e estadual) nas comarcas e distritos em que atuam?; (ii) avaliação das perguntas 2 a 4 - o Promotor de Justiça tem clareza e sabe discernir os objetivos das principais estratégias de conservação presentes em suas comarcas?; (iii) avaliação da pergunta 05 - a estrutura de trabalho satisfaz as condições mínimas necessárias para o cumprimento da missão funcional?; (iv) avaliação da pergunta 06 - o direito ambiental é uma das três áreas de maior preferência de atuação?; (v) avaliação da pergunta 07 - o Promotor reconhece as vias extrajudiciais como instrumentos eficazes de atuação para a mitigação, reparação ou impedimento do dano ambiental?

\section{A defesa ambiental: entre o discurso e a prática}

O trabalho em tela observou que dos 23 Promotores de Justiça, 13 estavam atentos quanto às diferentes estratégias de conservação vigentes em suas comarcas, ainda que todas as 23 comarcas possuíssem ao menos uma categoria de unidade de conservação estadual ou federal reconhecida. Assim, tal constatação se confirma quando apenas 11 promotores do total de entrevistados tinham na memória os nomes das unidades, lembrando-se, de imediato, de tais áreas protegidas e citando com precisão os seus nomes. Esta acuidade mnemônica também se reflete nos TACs acessados nas comarcas, pois apesar de abrigarem UC em seus limites territoriais, em nenhum Termo estas áreas protegidas foram citadas. Importa ressaltar que fato similar foi constatado por Ramos e Trevizan (2005) ao analisarem a persecução dos crimes ambientais contra a Mata Atlântica no Sul da Bahia. Tendo como objeto de estudo as comunicações de autos de infração (emitidas por fiscais do IBAMA e encaminhadas ao MP), os pesquisadores não observaram nenhuma autuação por dano em unidades de conservação, consoante ao art. 40 da Lei Penal Ambiental (9.985/1998). Esperavam estes, ao contrário, elevada probabilidade de ocorrência de autos de infração pautados naquele artigo, vez que na área abrangida por tal pesquisa ocorrem diversas unidades de conservação.

Diante da pergunta relativa ao entendimento do órgão ministerial acerca do Corredor Ecológico - pergunta quatro - identifica-se que 15 Promotores responderam nos termos que se aproximam da visão acadêmica da Biologia da Conservação (ROCHA et al., 2006), embora destacando apenas um dos aspectos da função do Corredor Ecológico, fazendo menção a essa estratégia como solução para sanar a extinção da fauna. Não explicitaram em suas falas o potencial específico do CE como uma estratégia de gestão de paisagem, conforme demonstra o DSC relativo à pergunta concernente ao corredor ecológico: "É a ligação entre pedaços de vegetação para permitir o fluxo da fauna, a fim de preservar a mata atlântica”.

Em resposta para a mesma pergunta, três dos entrevistados desconheciam o significado de corredores ou não tinham nenhuma noção da importância dessa estratégia de conservação para o bioma Mata Atlântica, embora trabalhem em comarcas contempladas pelo Projeto Corredores Ecológicos. O NuMA também divulga o Projeto Corredores durante as capacitações realizadas para os Promotores de Justiça da Bahia (NUMA, 2007).

É ainda muito incipiente o conhecimento que a maioria dos membros entrevistados do MP apresenta quanto ao conceito biológico do bioma Mata Atlântica, bem assim da sua importância para o equilíbrio ecológico, conforme se lê no DSC, em resposta à pergunta 3: "É uma floresta que ia do Rio Grande do Norte ao Rio Grande do Sul que hoje se encontra reduzida de 7 a $8 \%$ e tem uma grande diversidade de fauna e flora".

O processo histórico de devastação da Mata Atlântica e o seu contexto no processo do desenvolvimento econômico do país (DEAN, 1997) são enunciados pelos Promotores, mas parco é o conhecimento que os operadores jurídicos revelam desse bioma, não sendo expresso o conceito apresentado nas normas jurídicas. Fato é que um Promotor apenas respondeu conceituando biologicamente a Mata Atlântica e observando algumas das suas particularidades, conforme descrevem as Resoluções do CONAMA n. ${ }^{\circ} 010$, de 01 de outubro de 1993 e n. ${ }^{\circ} 005$, de 04 de maio de 1994. Constatou-se que estes Operadores do Direito tendem a 
conceituar o bioma em questão relevando as fisionomias florestais (florestas ombrófilas e estacionais) e relegando a uma posição secundária, seja por não mencionar, seja por não enfatizar quando mencionam os ecossistemas associados (manguezais, restingas e brejos interioranos). Por outro lado, alguns entrevistados sequer reconheceram os ecossistemas associados como parte integrante do bioma Mata Atlântica.

Em avaliação da estrutura interna do trabalho ministerial, os Promotores de Justiça do NuMA reconhecem melhorias significativas, porquanto a instituição lhes provê equipamentos e recursos materiais em tempo ágil. As condições de trabalho foram consideradas satisfatórias para o cumprimento da missão funcional por 15 entrevistados, enquanto seis Promotores declararam que as condições não os satisfaziam. Do total dos 23 Promotores, 17 identificaram que as condições de trabalho melhoraram significativamente, conforme ilustra o Gráfico 1. Contudo, todos os 23 foram unânimes quanto à falta de: (i) recursos que viabilizem a investigação e condenação dos que praticam crimes ambientais; (ii) equipamentos essenciais; (iii) peritos ambientais; (iv) estrutura do poder executivo para exercer a função de fiscalização, apreensão e prisão, o que reflete negativamente na atuação do Promotor de Justiça.

Os entrevistados, na sua totalidade, reconheceram o acúmulo de serviços e atribuições dos promotores e a pouca colaboração do poder judiciário para agilizar o andamento dos processos, tal qual ilustra o conteúdo do DSC no depoimento relativo à pergunta número 5 :

Há carência de corpo técnico, única Promotoria e jurisdição plena. Há acúmulo de atribuições existentes em comarca de promotoria única, onde o promotor é cível, é penal, é consumidor, é infância, é meio ambiente, é patrimônio público, é trabalho judicial, é trabalho extrajudicial. Sem falar da questão da atuação judicial, porque o promotor tem que fazer audiências, atuar judicialmente nos processos, seja como fiscal da lei, seja como parte. E conciliar tudo isso com a questão ainda extrajudicial, que a cada dia tem sido ampliada pela legislação com o conhecimento da atuação do MP. Também falta estrutura para as entidades de apoio.

Quanto ao reconhecimento das vias extrajudiciais como instrumentos eficazes de atuação ministerial, os Promotores declararam:

Melhor via é a extrajudicial. A solução é mais rápida e nós fiscalizamos. É menos burocrática e com estes temos mais autonomia de atuação. A Ação Civil Pública é o último recurso, é a medida extrema. A via judicial é

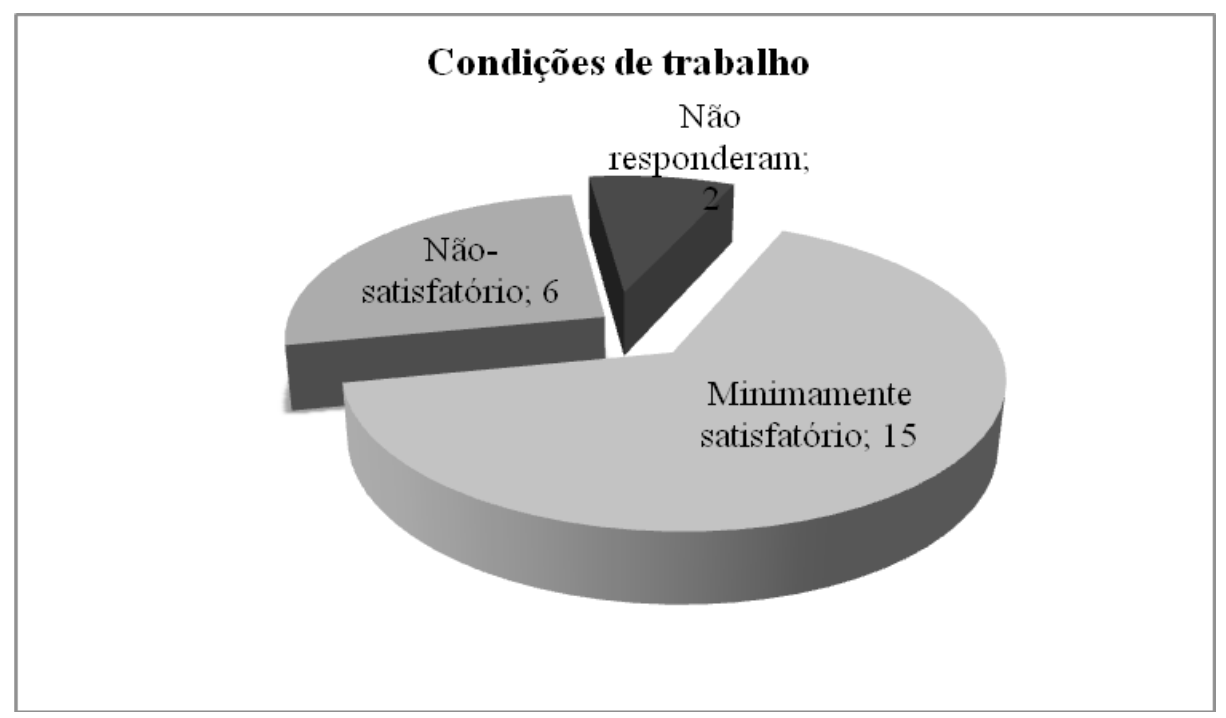

GRÁFICO 1 - DISCURSO COLETIVO DOS PROMOTORES. 
lenta e o meio ambiente não espera, porque a degradação ambiental é mais veloz do que qualquer via judicial. Todos nós sabemos das dificuldades do poder judiciário.

Não obstante a importância referida pelos entrevistados do esforço para realização de pactos, os dados disponíveis não revelam na sua totalidade esta atuação de caráter negocial da lide, exposto no Gráfico 2.

\section{Levantamento documental: Andamento dos TAC}

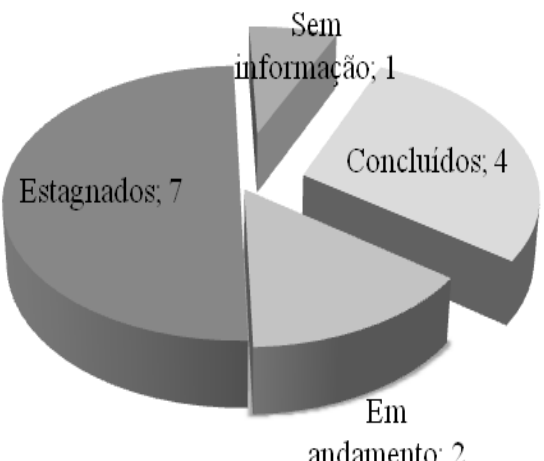

GRÁFICO 2 - VERIFICAÇÃO DOS TERMOS DE AJUSTAMENTO DE CONDUTA - TAC.

Analisando-se os procedimentos das 22 comarcas verificou-se que de 14 TACs apenas quatro foram concluídos dentro do prazo de um ano, em um não havia informação suficiente para inferir, dois ainda estavam em andamento e sete demonstravam encontrar-se estagnados em face do intervalo de mais de um ano entre o penúltimo ato e último ato. Com exceção destes 14 TAC, houve menção de outros três acordos (não disponíveis) em inquéritos civis distintos, cujas informações disponíveis foram: (i) comarca que ajuizou o inquérito; (ii) data de instauração do inquérito; (iii) identificação do investigado; (iv) objeto da investigação; (v) se houve produção de provas e quem produziu; (vi) a medida adotada: TAC; (vii) se houve arquivamento e remessa dos autos ao Conselho Superior do MP. Dos três inquéritos supracitados, dois registraram (no campo informações relevantes) que os TACs ocorreram na APA Estadual de Itacaré - Serra Grande.

Consoante aos sete termos de ajustamento estagnados, em apenas dois houve descrição exata das condições de tempo (prazo), modo (como e o que fazer) e lugar do cumprimento das obrigações para a reparação ou cessação do dano ambiental. Em um destes sete TACs houve, por parte da Promotoria, estabelecimento de critérios para constatar o cumprimento das obrigações e em nenhum houve averiguação do cumprimento do acordo extrajudicial.

A afinidade com o tema do direito ambiental foi outro objeto das entrevistas e verificou-se que somente cinco Promotores têm predileção expressa pelo direito ambiental, em comparação às outras áreas de atuação. De fato, o direito ambiental não é prioridade, reflexo de demandas de maior repercussão na mídia e na sociedade: improbidade administrativa, direito da criança e do adolescente, direito do consumidor e direito penal.

Nota-se, no discurso coletivo dos Promotores, que as UCs são percebidas como instrumentos de proteção jurídica da natureza, análogos às Áreas de Preservação Permanente -APP, às Reservas Legais - RL e aos corredores ecológicos (BENJAMIM, 2003), havendo, todavia, dificuldade de distinção quanto aos objetivos específicos destes e os das UCs previstos na Norma Legal (Lei 9.985/2000) que institui o SNUC. Assim, na análise das entrevistas, tem-se que 15 dos 23 entrevistados revelam que "ainda não se apropriaram das definições e dos objetivos dessas principais estratégias de conservação", conforme o conteúdo das próprias respostas (HONORATO et al., 2009).

Neste mesmo esteio, o conjunto das respostas revela que não houve, até então, o reconhecimento de que o projeto Corredores Ecológicos do MMA constitui uma estratégia política, que também trata das relações institucionais, construindo e propondo interlocução com a comunidade científica e aproximando as UCs também às terras indígenas e às áreas com diferentes formas de uso de terra, capazes de potencializar a conservação do bioma.

Segundo se depreende do conjunto de entrevistas e peças examinadas, a limitação do MP, no que se refere ao domínio dos conceitos básicos do bioma em questão e seus ecossistemas associados, dificulta a negociação extrajudicial na medida em que o operador do Direito passa a ter limitada precisão quanto ao objeto a ser defendido, constatando a urgência do Ministério Público vir a contar com atuação interativa entre promotores e peritos especializados na matéria ambiental.

No que diz respeito à preferência dos Promotores entrevistados às vias extrajudiciais, especialmente o TAC, Capelli (2003) igualmente enumera as vantagens: (i) 
abrangência do termo de ajustamento à decisão judicial, em face dos reflexos criminais e administrativos; (ii) menor custo; (iii) maior reflexo social da solução extrajudicial, ao permitir o trato do problema sob variados aspectos (ecossistemas, bacias hidrográficas e outros assuntos); (iv) propicia diretamente o conhecimento dos problemas, mediante investigação e seu desdobramento; (v) a prova é coligida sem intermediários; (vi) a solução do problema somente é adotada após diversas reuniões, negociações e decisão consensual envolvendo poder público, sociedade civil e técnicos (CAPELLI, 2003).

Por seu turno, a mesma autora grifa algumas das limitações das vias judiciais: i) morosidade no julgamento das demandas e ii) visão privatista da propriedade e opção pelos valores da livre iniciativa e do crescimento econômico por parte dos que apreciam a matéria.

Acerca do TAC, houve, porém, um descompasso entre o discurso coletivo dos promotores e a eficiência da sua utilização nas promotorias. Depreende-se que uma das causas desse ônus é a grande rotatividade dos promotores nas comarcas em consequência das promoções previstas na carreira destes membros do Parquet, imprimindo descontinuidade nos acordos extrajudiciais e fragilidade no monitoramento e cumprimento dos prazos estabelecidos para o exercício das obrigações do compromissário. Conforme salientado anteriormente, sem o calço do direito ambiental, exercido por promotor de justiça especializado e/ou perito ambiental, o órgão assume a impossibilidade da reversão das lesões ambientais e oferece a denúncia ao Juizado de Pequenas Causas, transformando o infrator em réu. Posto isso, havendo degradação, negligencia-se o fato de que o acordo extrajudicial se constitui em uma poderosa ferramenta para negociar celeridade à recuperação da área degradada, ao passo que evita "a morosidade do sistema penal e as muitas oportunidades oferecidas para o exercício do contraditório e da defesa"4 (BRASIL, 2005, p. 32). Igualmente, diminui a chance de sensibilizar o infrator, porquanto a possibilidade de inserção e integração deste em programas educativos e socioprodutivos pode ressignificar a construção da sua ética e dos seus valores (FINK, 2002). ${ }^{4}$ Frase extraída da Decisão Judicial do TRF 1. ${ }^{a}$ Região Quarta Turma - RCCR 2002.34.00.016934-9/DF - Rel. Ítalo Fioravanti Sabo Mendes - publicado no DJ de 19/09/2005.

\section{Considerações finais}

Apesar da maioria dos Promotores de Justiça estar atento às estratégias de conservação, a limitada clareza quanto aos objetivos da conservação limita o exercício ministerial em favor das unidades de conservação, mesmo com a afeição que nutrem pela área ambiental. As deficiências concernentes à infraestrutura, pessoal e equipamentos limitam a defesa das unidades de conservação, uma vez que o objeto do acordo para agilizar a mitigação do dano não acontece. Com efeito, em não havendo o monitoramento do acordo estabelecido, o infrator, com a sensação de impunidade, continua praticando o ilícito ambiental.

Em que pese os depoimentos dos Promotores revelarem o interesse quanto à eficácia na utilização das vias extrajudiciais, conclui-se que os Termos de Ajustamento de Conduta negociados em tais comarcas, no período entre 2004-2006, não surtiram efeitos concretos para impedimento, reparação ou reversão do dano ambiental.

A abrangência de atuação do MP é definida na Constituição Federal de 1988 e consolidada na conquista de densificação da prática ministerial em diferentes áreas. A criação do NuMA foi um indicador de corresponsabilidade ministerial diante da complexidade do cenário da Mata Atlântica. O MP dispõe de livre acesso a todo local onde se encontre a Unidade de Conservação, aos documentos e às provas que possam comprometer o bem ambiental. Dispõe este órgão, ademais, de todas as prerrogativas para defesa intransigente do patrimônio da humanidade. No entanto, a efetiva defesa das Unidades de Conservação exige o domínio técnico e a articulação interdisciplinar que demandam tempo, estudo, fortalecimento institucional mediante especialização contínua dos operadores jurídicos e interação com os peritos ambientais. Cada TAC pode vir a ser uma iniciativa de conservação de cada Área de Proteção Ambiental, mas pode correr o risco de ser, tão somente, um silêncio negociado e de papel passado: a diferença estará, sempre, no compromisso e na especialização do órgão ministerial. Longe de qualquer afinidade subjetiva, a proteção ambiental demanda, entre muitas outras medidas, profissionais jurídicos que dominem o tema e nele se especializem, construindo como escolha o cuidado com a vida em todas as suas formas. 


\section{Referências}

AGUiAR, A. P.; CHIARELlO, A. G.; MENDES, S. L.; MATOS, E. N. Os Corredores Central e da Serra do Mar na Mata Atlântica brasileira. In: GALINDO-LEAL, C.; CÂMARA, I. G. (Eds.) Mata Atlântica: biodiversidade, ameaças e perspectivas. Belo Horizonte: Fundação SOS Mata Atlântica, Conservação Internacional, Centro de Ciências Aplicadas à Biodiversidade, 2005.

ALBERTI, V. Manual de história oral. 2. ed. Rio de Janeiro: Fundação Getúlio Vargas, 2004.

AYRES, J. M.; FONSECA, G. A. B.; RYLANDS, A. B.; QUEIROZ, H. L; PINTO, L. P. S; MASTERSON, D.; CAVALCANTI, R.. Abordagens inovadoras para a conservação da biodiversidade do Brasil: os corredores ecológicos nas florestas neotropicais do Brasil - versão 3.0. Programa-Piloto para a Proteção das Florestas Neotropicais. Projeto Parques e Reservas. Ministério do Meio Ambiente, Recursos Hídricos e da Amazônia Legal (MMA). Instituto Brasileiro do Meio Ambiente e dos Recursos Naturais Renováveis (IBAMA). Brasília, 1997.

BAHIA. Lei Complementar Estadual n. 11, de 18 de janeiro de 1996. Institui a Lei Orgânica do Ministério Público. Salvador: DOE de 19/10/1996.

BEIER, P.; NOSS, R. F. Do habitat corridors provide connectivity? Conservation Biology, v. 2, n. 6, p. 1241-1252, 1998.

BENJAMIN, A. H. V. Introdução ao direito ambiental brasileiro. In: SOARES Jr., J.; GALVÃO, F. (Coord.). Direito ambiental na visão da magistratura e do Ministério Público. Belo Horizonte: Del Rey, 2003.

BRASIL. Ministério do Meio Ambiente. Avaliação e ações prioritárias para a conservação da biodiversidade da mata atlântica e campos sulinos. Brasília: Ministério do Meio Ambiente, Fundação SOS Mata Atlântica, Fundação Biodiversitas, Instituto de Pesquisas Ecológicas, Secretaria do Meio Ambiente do Estado de São Paulo, SEMAD/Instituto Estadual de Florestas - MG. 2000. 40 p.

TRF. $1^{a}$ região. RCCR 2002.34.00.016934 - 9/DF Rel. Ítalo Fioravanti Sabo Mendes, 4. ${ }^{\mathrm{a}} \mathrm{T}$, Data do Julgamento 08/8/2005, DJU/II 19/09/2005, p. 32. Disponível em: <http:// www.conjur.com.br/2006-set-2/justica_federal_autoriza_remocao_moradores_df $>$. Acesso em: 14.11.2010.

. Lei Federal 9.985, de 18 de julho de 2000. Regulamenta $\mathrm{o}$ art. 225, § 1. ${ }^{\circ}$, incisos I, II, III e VII da Constituição Federal, institui o Sistema Nacional de Unidades de Conser- vação da Natureza - SNUC e dá outras providências. Brasília: DOU de 23/08/2002.

. Ministério do Meio Ambiente. O Corredor Central da Mata Atlântica: uma nova escala de conservação da biodiversidade. Brasília: Ministério do Meio Ambiente; Conservação Internacional. 2005. 46 p.

Constituição da República Federativa do Brasil de 1988. Disponível em: <https://www.planalto.gov.br/ccivil_03/ Constituicao/Constitui\%C3\%A7ao.htm>. Acesso em: 18 out. 2006.

CÂMARA, I. de G. As unidades de conservação e o paradigma de Durban. Natureza \& Conservação, v. 2, n. 2, p. 8-14, 2004.

CAPPELLI, S. Atuação extrajudicial do Ministério Público na tutela do meio ambiente. In: SOARES Jr., J.; GALVÃO, F. (Coord.). Direito ambiental na visão da magistratura e do Ministério Público. Belo Horizonte: Del Rey, 2003.

CORDEIRO, P. H. C. Análise dos padrões de distribuição geográfica das aves endêmicas da mata atlântica e a importância do corredor da serra do mar e do Corredor Central para a conservação da biodiversidade brasileira. In: PRADO, P. I.; LANDAU, E. C.; MOURA, R. T.; PINTO, L. P. S.; FONSECA, G. A. B.; ALGER, K. (Org.). Corredor de biodiversidade da Mata Atlântica do sul da Bahia. Ilhéus: IESB/CI/CABS/ UFMG/Unicamp. CD-ROM, 2003.

COSTA Neto, N. D. de C. Proteção jurídica do Meio ambiente - I. Florestas. Belo Horizonte: Del Rey, 2003.

DEAN, W. A ferro e fogo: a história e a devastação da Mata Atlântica brasileira. São Paulo: Companhia das Letras, 1997.

FINK, D. R. Alternativa à ação civil pública ambiental (reflexões sobre as vantagens do termo de ajustamento de conduta). In: MILARÉ, E. (Coord.). Ação civil pública: Lei 7437/85-15 anos. São Paulo: Revista dos Tribunais, 2002.

FLORIANI, D. C.; SCHEIBE, L. F.; POLETTE, M. Aplicação da análise da cadeia casual em unidades de conservação. Um estudo de caso: Área de Proteção Ambiental do Anhatomirim (SC - Brasil). Natureza \& Conservação, v. 5, n. 1, p. 45-53, 2007.

FONTES, P. G. G. O controle da administração pelo Ministério Público. Belo Horizonte: Del Rey, 2006.

GALINDO-LEAL, C.; CÂMARA, I. G. Status do hotspot Mata Atlântica: uma síntese. In: GALINDO-LEAL, C.; CÂMARA, I. G. (Eds.). Mata Atlântica: biodiversidade, ameaças e perspectivas. Belo Horizonte: Fundação SOS Mata Atlântica, 
Conservação Internacional e Centro de Ciências Aplicadas à Biodiversidade, 2005.

GANEM, R. S. Corredores ecológicos: o que são? In: ARRUDA, M. B. (Org.). Gestão integrada de ecossistemas aplicada a corredores ecológicos. Brasília: Ibama, p. 85-100, 2005.

HANSKI, I. Metapopulation dynamics. Nature, n. 396, p. 41-49, 1998.

HONORATO, S. C.; LIMA, I. M. S. O.; FARIA, D. M. de. O Ministério Público e as Unidades de Conservação. Natureza \& Conservação, v. 8. n. 1, p. 1-5, 2010.

; MENDES, S. Políticas públicas e proteção ambiental: o papel do Ministério Público nas Unidades de Conservação no sul da Bahia. In: Fundação O Boticário de Proteção à Natureza. CONGRESSO BRASILEIRO DE UNIDADES DE CONSERVAÇÃO, 6., Curitiba, set. 2009. Anais...

IBGE - INSTITUTO BRASILEIRO DE GEOGRAFIA E ESTATÍSTICA. Comunicação social de 12 de maio de 2004. Disponível em: <http:/www.ibge.gov.br/home/presidencia/ noticias/noticia_viasualiza.php?id_noticia $=169>$. Acesso em: 28 set. 2010.

LANDAU, E. C.; RESENDE, N. A. T. Unidades de Conservação do Sudeste da Bahia, Brasil - mapa em formato digital elaborado a partir de INCRA, 1998; CRA, 1998 e dados inéditos, escala 1:250.000. In: PRADO, P. I.; LANDAU, E. C.; MOURA, R. T.; PINTO, L. P. S.; FONSECA, G. A. B.; ALGER, K. (Orgs.). Corredor de Biodiversidade da Mata Atlântica do Sul da Bahia. 1 CD-ROM. IESB/CI/CABS/ UFMG/UNICAMP, 2003.

LEFEVRE, F.; LEFREVE, A. M. C. O discurso do sujeito coletivo. Um novo enfoque em pesquisa qualitativa. Caxias do Sul: Educs, 2005.

MACHADO, P. A. L. Direito Ambiental Brasileiro. 14 ed. rev., atual. e ampl. São Paulo: Malheiros Editores, 2006.

MESQUITA, C. A. B.; TEBALDI, A. L. C.; BRAVO, R. M.A.; BERBERT, L. de M.; CUNHA, R. S. da; ALBUQUERQUE Jr, J. de; SANT'ANNA, A. L. V. Diagnóstico das unidades de conservação do Corredor Central da Mata Atlântica na Bahia. Ilhéus: MMA. Mimeo. 2004. Relatório.

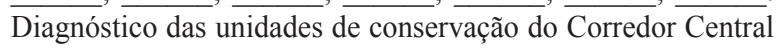
da Mata Atlântica. In: NUNES, M. de L.; TAKAHASHI, L.; THEULEN, V. (Orgs). V CONGRESSO BRASILEIRO DE UNIDADES DE CONSERVAÇÃO, jun. 2007. Foz do Iguaçu. Anais. MMA - MINISTÉRIO DO MEIO AMBIENTE. Avaliação e identificação de áreas prioritárias para a conservação, utiliza- ção sustentável e repartição dos benefícios da biodiversidade nos biomas brasileiros. Brasília: MMA, Probio, 2002.

MORI, S. A.; BOOM, B. M.; CARVALHO, A. M.; SANTOS, T. S. Southern Bahian moist forests. The Botanical Review, v. 49, n. 2, p. 155-226, 1983.

NuMA - Núcleo da Mata Atlântica do Ministério Público. Oficinas Ambientais do Núcleo da Mata Atlântica do Ministério Público, I a IV. Bahia: NuMA, Relatório, 2007.

PRADO, P. I.; LANDAU, E. C.; MOURA, R. T.; PINTO, L. P. S.; FONSECA, G. A. B.; ALGER, K. (Org.). Corredor de biodiversidade da mata atlântica do sul da Bahia. Ilhéus: IESB/ CI/CABS/UFMG/Unicamp, CD-ROM, 2003.

RAMBALDI, D. M.; OLIVEIRA, D. A. S. (Org.). Fragmentação de ecossistemas: causas, efeitos sobre a biodiversidade e recomendações de políticas públicas. Brasília: MMA/SBF, 2003. 510 p.

RAMOS, A. D.; TREVIZAN, S. D. P. Persecução criminal de delitos contra a flora no sul da Bahia. Revista Baiana de Tecnologia, v. 20, n. 2-3, p. 116-127, 2005.

ROCHA, C. F. D.; BERGALLO, H. G.; SLUYS, M. V.; ALVES, M. A. S.; JENKINS, C. Corredores ecológicos e conservação da biodiversidade: um estudo de caso na Mata Atlântica. In: ROCHA, C. F. D.; BERGALLO, H. G.; SLUYS, M. V.; ALVES, M. A. S. (Eds.). Biologia da conservação: essências. São Carlos: RiMa, 2006.

SILVA, J. M. C. da; CASTELETI, C. H. M. Estado da biodiversidade da Mata Atlântica brasileira. In: GALINDO-LEAL, C.; CÂMARA, I. G. (Eds.) Mata Atlântica: biodiversidade, ameaças e perspectivas. Belo Horizonte: Fundação SOS Mata Atlântica, Conservação Internacional e Centro de Ciências Aplicadas À Biodiversidade, 2005.

TABARELLI, M.; PINTO, L. P.; SILVA, J. M. C.; HIROTA, M. M.; BEDÊ, L. C. Desafios para a conservação da biodiversidade na Mata Atlântica Brasileira. Megadiversidade, v. 1, n. 1, p. 132-138, 2005.

TEIXEIRA, F. D. Princípios constitucionais do Ministério Público. Revista Brasileira de Ciências Criminais, v. 12, n. 49, p. 291-315, 2004.

THEULEN, V. Manejo e gerenciamento das unidades de conservação federais segundo a percepção dos seus chefes. Natureza \& Conservação, v. 2, n. 2, p. 66-76, 2004.

Recebido em março de 2010.

Aceito em setembro de 2010. Publicado em dezembro de 2010. 